\title{
Estudo de Depósitos da Formação Barreiras com Base em Reflexão por Ondas de Radar
}

\author{
Paula de Freitas Santos' (pfsantos@gmail.com), Claudio Limeira Mello', \\ Rute Maria Oliveira de Morais'1,2, Carolina da Silva Ribeiro' \\ 'Departamento de Geologia - IGEO/CCMN - UFRJ \\ Av. Brigadeiro Trompowski s/n, CEP 21941-590, Rio de Janeiro, RJ, BRA \\ ${ }^{2}$ PETROBRAS/E\&P-EXP/IABS/OS, Rio de Janeiro, RJ, BRA
}

Recebido em 07 de fevereiro de 2006; aceito em 13 de junho de 2006

Palavras-chave: Formação Barreiras, fácies de radar, Sudeste do Brasil.

\section{RESUMO}

Este trabalho trata de um estudo em subsuperfície de depósitos da Formação Barreiras em localidades selecionadas no norte do Estado do Rio de Janeiro e no sul do Estado do Espírito Santo, integrando seções de reflexão por ondas de radar ( $G P R$ - radar de penetração subterrânea ou georradar) a perfis litológicos de furos de sondagens. Três seções de $G P R$ foram investigadas pelo modo de afastamento comum, utilizando-se o sistema GPR pulseEkko IV, com antenas de $50 \mathrm{MHz}$. Com base na interpretação das linhas geofísicas, enfatizando a identificação das principais fácies e unidades de radar, foram selecionados pontos para furos de sondagens, com trado mecânico. Os depósitos da Formação Barreiras aqui estudados correspondem a sucessões arenosas granodecrescentes, mosqueadas e com estratificações cruzadas, que estão relacionadas, na investigação geofísica, a um padrão de refletores ondulados, mais ou menos contínuos, de aspecto entrecruzado, com geometria côncava para cima (fácies de radar II), intercaladas a camadas tabulares de lamitos argilosos, às vezes bioturbados, associadas a um padrão de refletores contínuos e paralelos (fácies de radar I). Os sedimentos da Formação Barreiras foram interpretados como depósitos de canais fluviais, com pouca participação de sedimentos de suspensão ou por fluxos gravitacionais, corroborando interpretações anteriores para depósitos aflorantes nestas regiões.

Keywords: Barreiras Formation, radar facies, Southeastern Brazil.

\section{ABSTRACT}

This paper integrates radar reflection sections (GPR - Ground Penetrating Radar) with lithologic profiles based on sounding logs in deposits of the Barreiras Formation at selected points in the northern part of Rio de Janeiro State and southern part of Espirito Santo State. Three radar survey lines were investigated by common-offset mode using PulseEkko IV radar system and $50 \mathrm{MHz}$ antennas. Based on interpretation of the main radar facies and units evident in the GPR lines, sampling points were selected for obtaining sounding logs using a mechanical auger. The Barreiras Formation deposits here described correspond to fining-upward sandy successions. In the geophysical survey, these sandy deposits are associated with more-or-less continuos wavy reflection patterns presenting a cross-bedded aspect and concave-upward geometry (radar facies II). Argillaceous mudstone layers interbedded with the sandy deposits are associated with a continuous, parallel reflection pattern (radar facies I). The Barreiras Formation sediments are interpreted as fluvial channel deposits, with little contribution of suspended sediments or gravitational flow deposits, in agreement with previous interpretations based on outcrop deposits in these regions. 


\section{INTRODUÇÃO}

Sob a denominação Formação Barreiras, são conhecidos sedimentos neogênicos de origem predominantemente continental a litorânea, arenosos e argilosos e de cores variegadas, que se distribuem ao longo do litoral brasileiro desde o Amapá até o Rio de Janeiro (Suguio e Nogueira, 1999).

No litoral Sudeste do Brasil, onde têm sido muito pouco estudados, esses sedimentos estendem-se desde o norte do Espírito Santo até a "Região dos Lagos", no Rio de Janeiro. No Estado do Espírito Santo, estes depósitos foram investigados por Amador e Dias (1978), Amador (1982) e Tamara (1995), que descreveram associações litológicas distintas, interpretadas como de ambientes fluviais. No Estado do Rio de Janeiro, foram recentemente reavaliados por Morais (2001), que os interpretou como relacionados a ambiente fluvial entrelaçado, com depósitos de fluxos gravitacionais; mais restritamente na região de Búzios, Morais (2001) relacionou-os a depósitos sob influência de leques aluviais dominados por fluxos gravitacionais.

Os trabalhos sobre a Formação Barreiras limitam-se quase somente a depósitos aflorantes, com poucos metros de espessura. Há uma necessidade de estudos em subsuperfície para o melhor conhecimento geológico desta unidade.

Estudos de subsuperfície com o uso do radar de penetração subterrânea $(G P R)$ em depósitos cenozóicos semelhantes à Formação Barreiras foram realizados por Madeira et al. (1997a, 1997b) e Madeira (2001), obtendo boa qualidade de penetração das ondas de radar e permitindo o estabelecimento das principais relações estratigráficas nestes depósitos.

O trabalho aqui apresentado versa sobre a aplicação do $G P R$ na investigação da Formação Barreiras em localidades selecionadas no norte do Estado do Rio de Janeiro e no sul do Estado do Espírito Santo (Figura 1), tendo sido investigadas áreas em que estes depósitos apresentam características distintas do ponto de vista da espessura e do grau de alteração/ferruginização.

\section{MÉTODOS E TÉCNICAS}

\section{Caracterização dos depósitos aflorantes}

A primeira etapa deste estudo consistiu na descrição litofaciológica, com o auxílio de fotomosaicos, de afloramentos selecionados na área de estudo, localizadas em cortes de estradas ou falésias ativas. A interpretação dos fotomosaicos enfatizou o reconhecimento da geometria das camadas e as eventuais variações litológicas. Em campo, as interpretações dos fotomosaicos foram conferidas, sendo elaborados perfis faciológicos verticais para cada seção estudada, identificando-se as fácies sedimentares com base na litologia, estruturas sedimentares, superfícies limitantes e, se presente, conteúdo fossilífero.

\section{Levantamento geofísico}

O radar de penetração subterrânea $(G P R)$, também conhecido como radar de subsuperfície ou georradar, é uma ferramenta de prospecção geofísica relativamente moderna, baseada em princípios eletromagnéticos, cujo uso na Geologia está difundindo-se em mapeamentos de feições estratigráficas e estruturas geológicas rasas. Além disso, o GPR também tem sido usado com sucesso na identificação de aquíferos, localização de cavidades de dissolução ou túneis, bem como em investigações arqueológicas (Harari, 1996).

No presente estudo, os dados geofísicos foram adquiridos com o equipamento GPR pulseEkko IV, utilizando antenas de $50 \mathrm{MHz}$ em caminhamentos contínuos, pelo modo de afastamento comum. Utilizou-se espaçamento de $2 \mathrm{~m}$ entre as antenas transmissora e receptora e intervalo de amostragem de $0,5 \mathrm{~m}$. Para o cálculo das velocidades de propagação das ondas de radar em subsuperfície, foi utilizado o modo $C M P$, em que as antenas de $50 \mathrm{MHz}$ foram afastadas de $40 \mathrm{em} 40 \mathrm{~cm}$, até atingirem um afastamento de 20 m. As imagens obtidas não passaram por etapas de processamento, exceto a correção da topografia, quando necessária. As seções geofísicas foram visualizadas e interpretadas utilizando-se os programas GRADIX e pulseEKKO.

Analogamente aos levantamentos sísmicos, o $G P R$ é um sistema de prospecção geofísica que fornece uma imagem contínua dos estratos em subsuperfície (radargrama), baseada nos padrões de reflexão que estes apresentam. Para a interpretação destas imagens podem ser aplicados, assim, os princípios da sismoestratigrafia, permitindo a interpretação estratigráfica e de sistemas deposicionais. Cada conjunto de refletores com configurações semelhantes corresponde a uma fácies de radar, e cada conjunto de refletores concordantes, limitados por superfícies discordantes, constitui uma unidade de radar.

\section{Sondagens}

Os padrões de reflexão de ondas de radar identificados e as suas interpretações permitiram selecionar pontos para a realização de furos de sondagens, com o objetivo de caracterizar os materiais em subsuperfície e correlacioná-los aos respectivos padrões de reflexão.

Os furos de sondagens foram executados com trado mecânico, sendo interrompidos ao atingir o embasamento cristalino ou quando o lençol freático impedia a recuperação de amostras. O material amostrado foi descrito quanto à granulometria, cor, seleção dos grãos e arredondamento. 


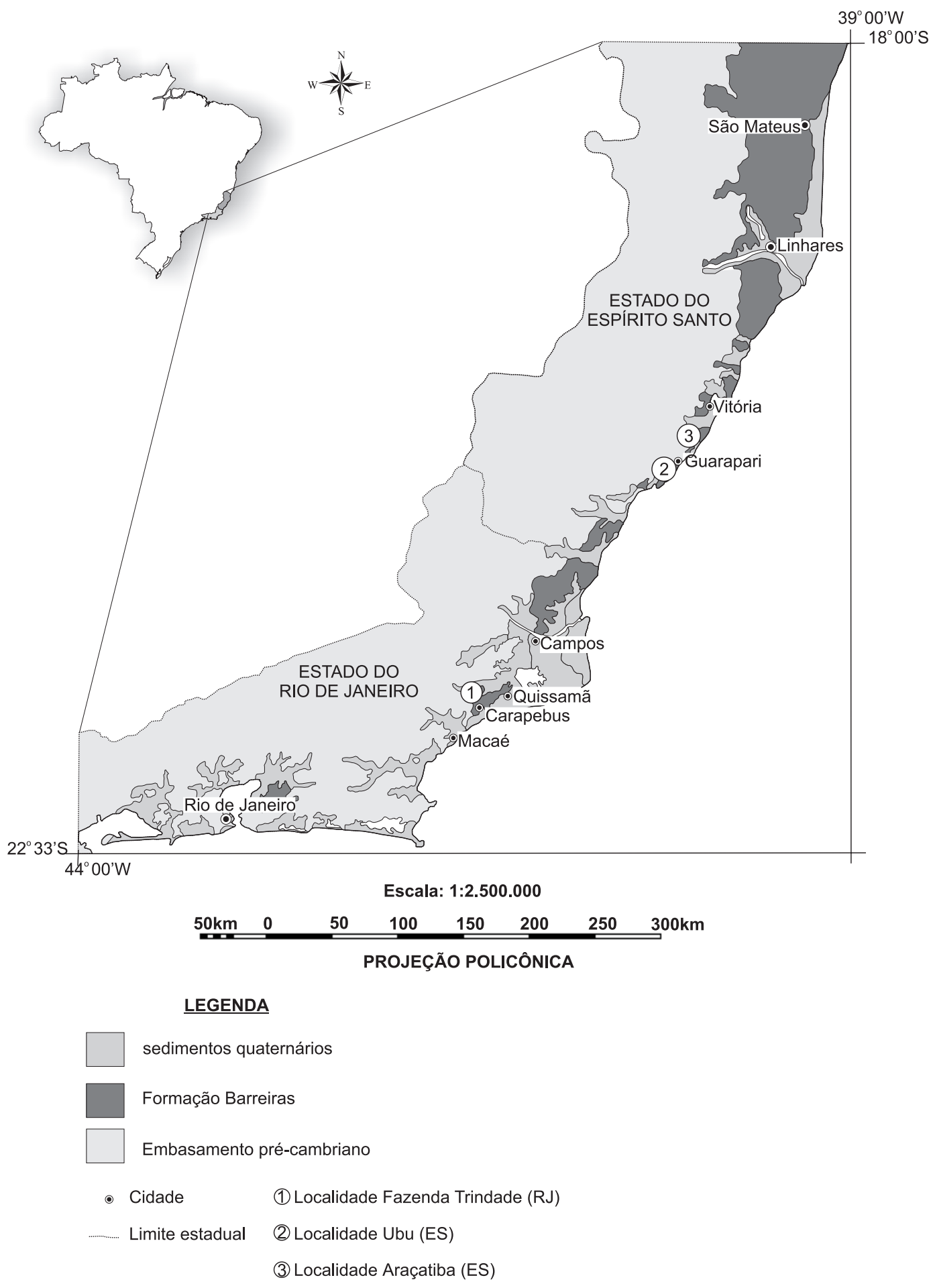

Figura 1. Mapa de localização das áreas investigadas neste trabalho (base geológica: Schobbenhaus et al. 1984, modificado). 


\section{RESULTADOS}

Com base na interpretação dos radargramas, foram individualizadas três fácies de radar (Tabela 1). Cada uma delas pôde ser associada a um conjunto litológico distinto. Estas fácies de radar distribuem-se nas diferentes unidades de radar, reconhecidas em cada localidade estudada, conforme apresentado a seguir.

\section{Localidade Fazenda Trindade (Quissamã, RJ)}

Na região entre as cidades de Quissamã e Carapebus, a sul de Campos dos Goytacazes, situa-se a segunda maior área de ocorrência da Formação Barreiras no Estado do Rio de Janeiro. Nesta região foi levantada uma seção geofísica na Fazenda Trindade, localizada na rodovia de acesso à cidade de Quissamã (RJ-196), cerca de $14 \mathrm{~km}$ a partir da BR-101. Esta seção situa-se em relevo de colina, estendendo-se desde o setor de baixa encosta até o topo, com um comprimento de $238 \mathrm{~m}$.

Nesta seção, foram identificadas quatro unidades de radar (Figura 2, Tabela 2). Ao longo da linha de prospecção geofísica, foram realizados dois furos de sondagens, atravessando as unidades de radar reconhecidas.

Na base do radargrama obtido na Fazenda Trindade, foi individualizada a unidade de radar "A", apresentando refletores em hipérboles convexas para cima, típicas da fácies de radar III. Sobre esta unidade, foram identificadas as unidades de radar "B" e "C", caracterizadas por refletores ondulados, levemente côncavos para cima, característicos da fácies de radar II. Acompanhando a superfície do terreno, na parte elevada da seção investigada, foi individualizada a unidade de radar " $D$ ", apresentando padrão de reflexão das ondas de radar característico da fácies de radar I.

De acordo com as descrições litológicas dos furos de sondagem realizados nesta localidade, a unidade de radar " $D$ " corresponde a materiais areno-argilosos, com níveis de cascalhos, associados a depósitos pós-Formação Barreiras. As unidades " $\mathrm{B}$ " e " $\mathrm{C}$ ” são compostas por materiais predominantemente arenosos, finos a grossos, distribuídos em sucessões granodecrescentes, às vezes intercalados a níveis argilosos pouco espessos, caracterizando depósitos da Formação Barreiras. No topo da unidade de radar "B", ocorrem também depósitos coluviais areno-argilosos (sedimentos pós-Formação Barreiras). $\mathrm{O}$ fato de estes depósitos não terem sido visualizados como uma unidade de radar à parte no radargrama deve-se a sua pequena espessura frente à resolução geofísica. A unidade de radar "A" corresponde a materiais síltico-argilosos, arroxeados e mosqueados, com características de rochas alteradas do embasamento.
Em um trecho exposto da encosta onde foi realizado o levantamento da seção geofísica, a visualização direta dos materiais investigados em subsuperfície (Figura 3) ilustra claramente as relações estratigráficas entre as unidades " $\mathrm{A}$ ", "B" e "C" descritas no radargrama, reproduzindo a mesma geometria de distribuição das unidades geológicas. Na seção geofísica, nota-se a unidade de radar "A" separando as unidades de radar "B" e "C", assim como ocorre na seção exposta a presença de rochas do embasamento alteradas separando materiais coluviais (topo da unidade de radar "B"), na porção topograficamente mais baixa da seção, dos depósitos da Formação Barreiras (unidade de radar "C"), aflorantes na porção mais alta. $\mathrm{O}$ forte refletor convexo para cima que separa, na seção geofísica, a unidade de radar "A" das outras duas unidades, está associado, na seção exposta, a níveis de seixos e blocos na base dos depósitos da Formação Barreiras e dos depósitos coluviais.

\section{Localidades Ubu e Araçatiba (sul do Espírito Santo)}

Na região sul do Estado do Espírito Santo, os depósitos da Formação Barreiras distribuem-se de modo descontínuo, ocupando áreas isoladas por altos do embasamento. Nesta região, foram investigadas duas localidades que apresentam boas exposições desta unidade estratigráfica, com características faciológicas bastante semelhantes, exibindo cerca de 10 m de seção aflorante do topo da Formação Barreiras, capeados por cerca de $2 \mathrm{~m}$ de cobertura areno-argilosa pós-Barreiras (Figuras 4 e 5).

Nos afloramentos, os depósitos da Formação Barreiras podem ser subdivididos em dois intervalos bem marcados. O intervalo inferior caracteriza-se por areias grossas a muito grossas, quartzosas, pouco feldspáticas, oxidadas, com estratificações cruzadas acanaladas bem desenvolvidas, em camadas lenticulares extensas compondo ciclos granodecrescentes; intercaladas aos depósitos arenosos, ocorrem camadas tabulares pouco espessas de lamitos arenosos a argilosos, esbranquiçados, maciços, com poucos grânulos e seixos de quartzo e feldspato, sendo observadas feições de bioturbação, bem evidenciadas na localidade Ubu. O intervalo superior é constituído por camadas tabulares de areias médias a grossas, maciças ou sem estrutura aparente, bastante mosqueadas, com cores avermelhadas.

$\mathrm{Na}$ seção geofísica estudada na localidade Ubu (Figura 6, Tabela 3), foram identificadas quatro unidades de radar. Na porção central do radargrama, verifica-se um registro de interferência externa que dificulta a interpretação da continuidade lateral das unidades de radar identificadas. As unidades de radar "F" e "G" são caracterizadas por refletores da fácies de radar I, enquanto que as unidades "E" e "H" apresentam geometrias lenticulares 



\begin{tabular}{l}
0 \\
0 \\
0 \\
0 \\
0 \\
0 \\
0 \\
0 \\
\hline
\end{tabular}

is

$\frac{0}{\frac{0}{0}}$

$\stackrel{\frac{2}{0}}{.=}$

$\frac{i}{\underline{0}}$

$\frac{0}{0}$

$\frac{0}{\frac{0}{0}}$

s

ㅇํㅇ

$\dot{\bar{\alpha}}$

$\stackrel{10}{\xi}$

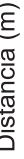

$\stackrel{\stackrel{\omega}{2}}{\underline{\sigma}}$

$\frac{0}{0}$

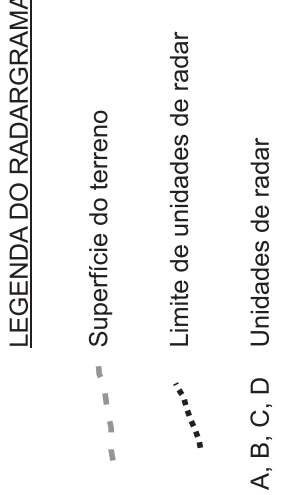

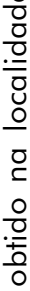

훙

흥 ผ

¿ क

ก $\stackrel{n}{0}$

옹

ํㅜㄴ 웅 
Tabela 1. Fácies de radar identificadas.

\begin{tabular}{|c|c|c|c|}
\hline Fácies & Descrição & Litologia & Representação \\
\hline Fácies de radar I & $\begin{array}{c}\text { padrão de refletores contínuos, } \\
\text { paralelos, às vezes pouco } \\
\text { irregulares }\end{array}$ & $\begin{array}{l}\text { areias finas, } \\
\text { predominantemente } \\
\text { argilosas, e lamitos }\end{array}$ & \\
\hline Fácies de radar II & $\begin{array}{l}\text { padrão de refletores ondulados, } \\
\text { mais ou menos contínuos, de } \\
\text { aspecto entrecruzado, com } \\
\text { geometria côncava para cima }\end{array}$ & $\begin{array}{l}\text { areias finas a grossas, } \\
\text { podendo ocorrer } \\
\text { intercalações de } \\
\text { sedimentos argilosos } \\
\end{array}$ & \\
\hline Fácies de radar III & $\begin{array}{l}\text { padrão de refletores marcado por } \\
\text { feições de hipérboles, convexas } \\
\text { para cima, ou refletores } \\
\text { fortemente inclinados, paralelos, } \\
\text { às vezes cruzados em "X" }\end{array}$ & $\begin{array}{c}\text { materiais argilosos, } \\
\text { bastante mosqueados e } \\
\text { com presença de crosta } \\
\text { de ferro }\end{array}$ & \\
\hline
\end{tabular}

Tabela 2. Síntese das feições de radar e correspondências litológica e estratigráfica na Fazenda Trindade (Quissamã, RJ).

\begin{tabular}{cccc}
\hline Unidade de radar & Fácies de radar & Aspectos litológicos & Unidade estratigráfica \\
\hline A & III & materiais argilo-sílticos & $\begin{array}{c}\text { rochas do embasamento } \\
\text { alteradas }\end{array}$ \\
\hline B & II & $\begin{array}{c}\text { pacotes arenosos } \\
\text { granodecrescentes, } \\
\text { recobertos por areias } \\
\text { argilosas }\end{array}$ & $\begin{array}{c}\text { Formação Barreiras e depósitos } \\
\text { coluviais pós-Barreiras }\end{array}$ \\
\hline C & II & $\begin{array}{c}\text { pacotes arenosos } \\
\text { granodecrescentes }\end{array}$ & Formação Barreiras \\
\hline D & I & areias argilosas & depósitos pós- Barreiras \\
\hline
\end{tabular}

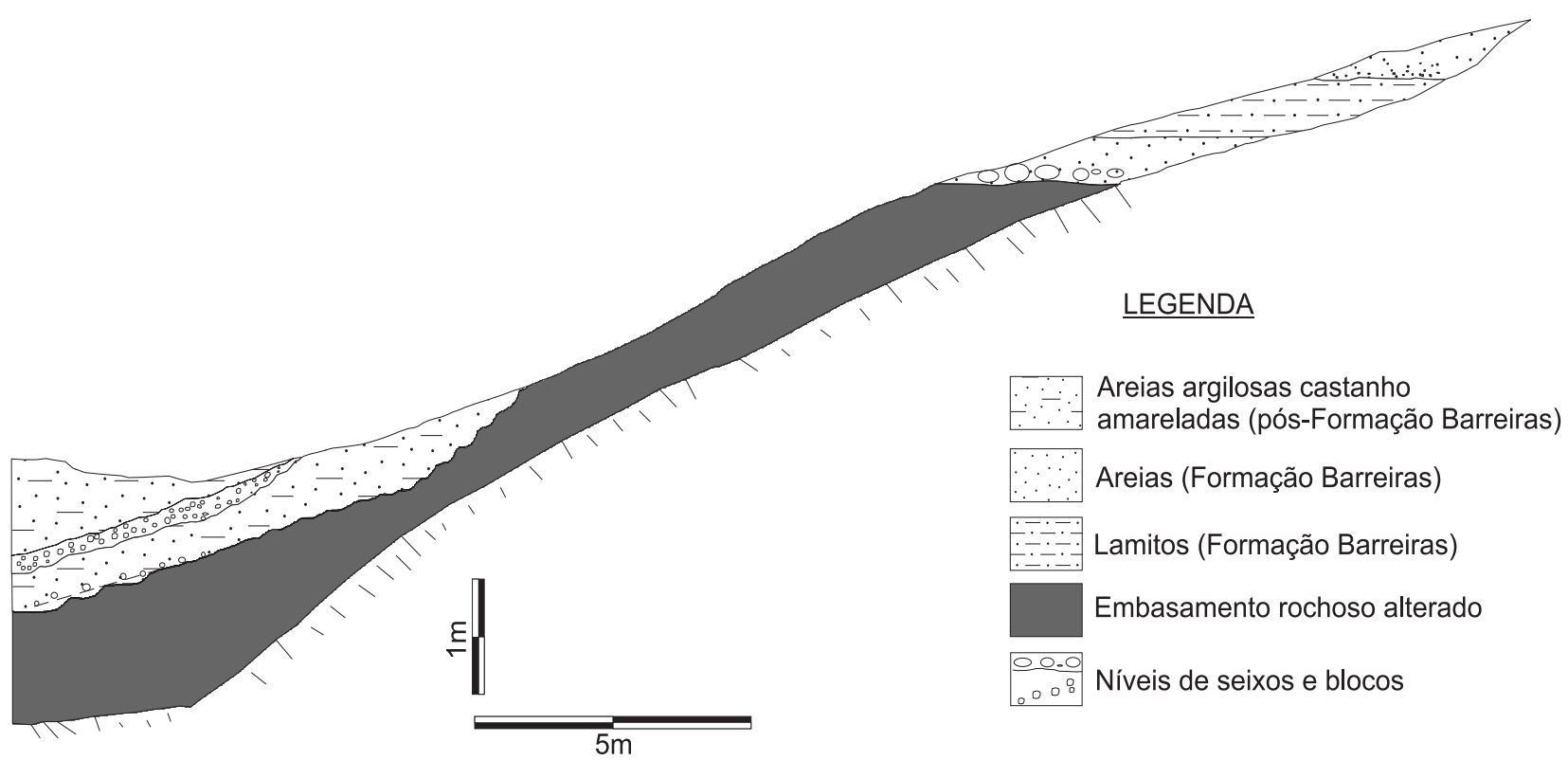

Figura 3. Afloramento da Formação Barreiras em trecho da encosta onde foi realizado o levantamento da seção geofísica na Fazenda Trindade (Quissamã, RJ) - vide localização na Figura 2. 


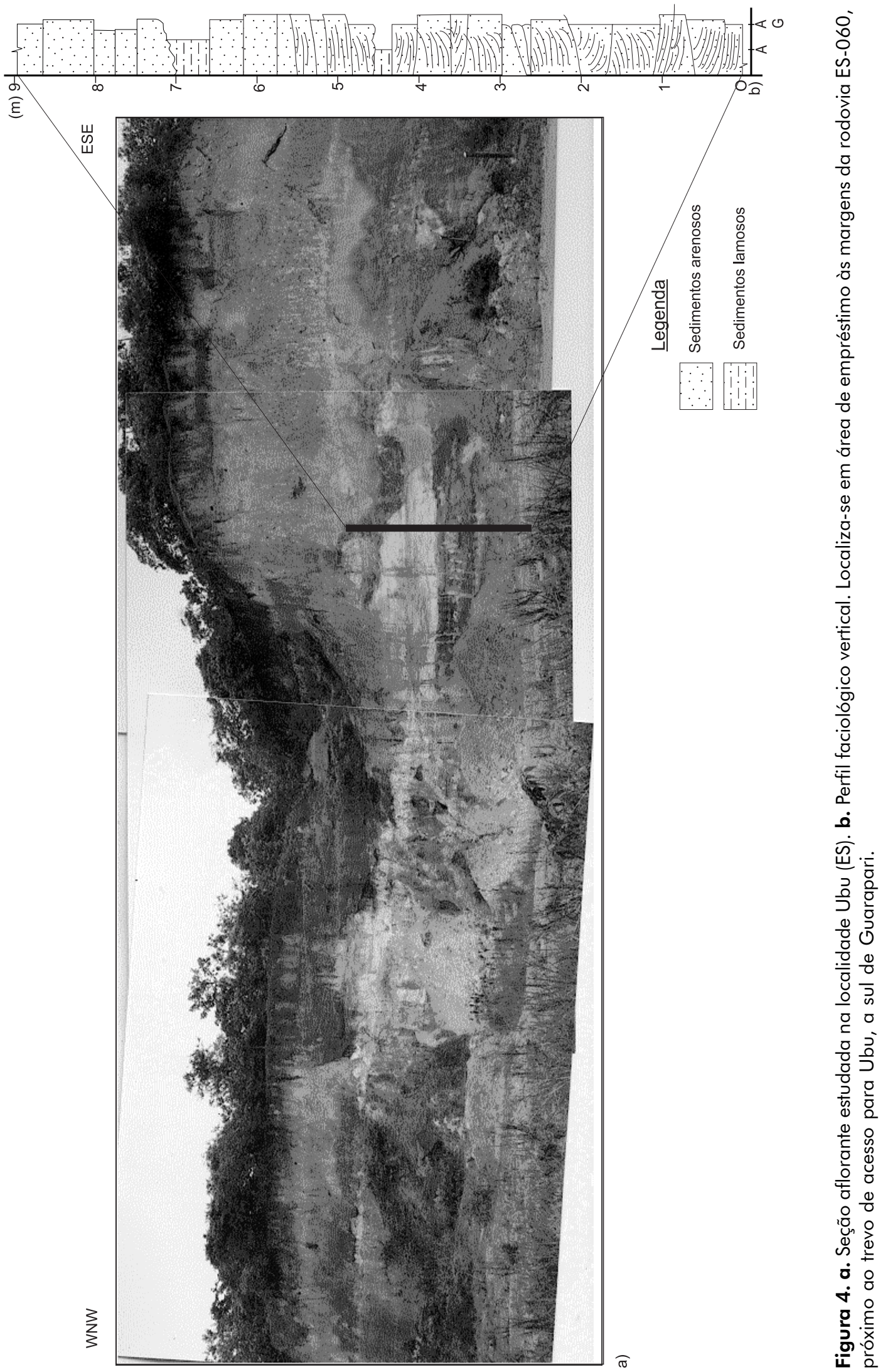




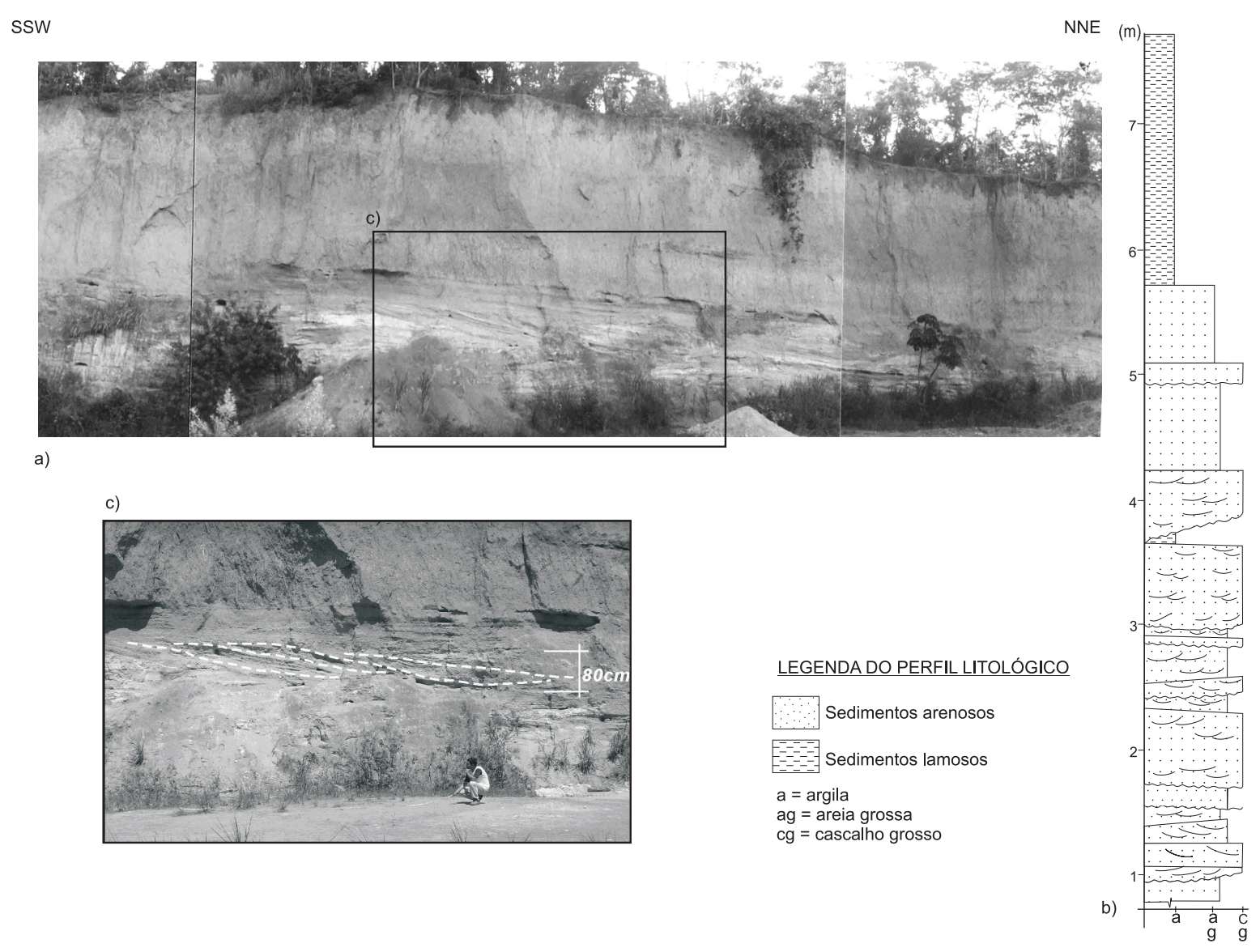

Figura 5. a. Seção aflorante estudada na localidade Araçatiba (ES). b. Perfil faciológico vertical. c. Detalhe dos depósitos arenosos na base da seção. Localizada no km 312 da BR-101, sentido norte-sul, entre Vitória e Guarapari.

preenchidas por refletores da fácies de radar II. A superfície que delimita a base da unidade " $\mathrm{H}$ " parece truncar a unidade de radar "G".

De acordo com as sondagens, as unidades de radar "F" e "G" correspondem a intercalações de camadas de areias finas a grossas, com alguma matriz argilosa (atribuída à alteração de grãos de feldspatos), esbranquiçadas a amareladas, e lamitos esbranquiçados a acinzentados, com grânulos dispersos. Estes sedimentos correspondem a depósitos da Formação Barreiras, em um padrão de sedimentação similar ao intervalo inferior da seção aflorante, embora com maior participação dos sedimentos lamosos. As unidades de radar "E" e "H" estão associadas a camadas de areias médias a grossas, intercaladas por camada de lamito, em padrão deposicional similar aos depósitos aflorantes da Formação Barreiras (intervalo inferior da seção exposta).

Na seção geofísica realizada em Araçatiba, também foram identificadas quatro unidades de radar (Figura 7, Tabela 4). As unidades de radar "I" e "J" possuem geometria lenticular e compreendem refletores contínuos, muito pouco ondu- lados, característicos da fácies de radar I. A visualização da continuidade lateral da unidade de radar "I", mais basal, foi prejudicada por sinais de interferência no radargrama. As unidades de radar "K" e "L" distribuem-se uma sobre a outra em formas de canais preenchidos por refletores mais ou menos contínuos, ondulados e côncavos para cima (fácies de radar II). A superfície que delimita a base da unidade "K" trunca as unidades "I" e "J". Os refletores internos nas unidades "K" e "L" organizam-se em um padrão progradantesigmoidal (Figura 7c), reproduzindo um aspecto deposicional observado no intervalo inferior da seção exposta nesta localidade, interpretado como o registro de migração lateral restrita dos canais fluviais (Figura 5c).

Através das descrições litológicas das sondagens, as unidades de radar "I" e "J" puderam ser relacionadas aos lamitos argilosos identificados na base do perfil S1, correspondendo a depósitos da Formação Barreiras. As unidades de radar "K" e "L" associam-se a camadas arenosas em sucessões granodecrescentes bem definidas, podendo incluir finas intercalações de lamitos. 

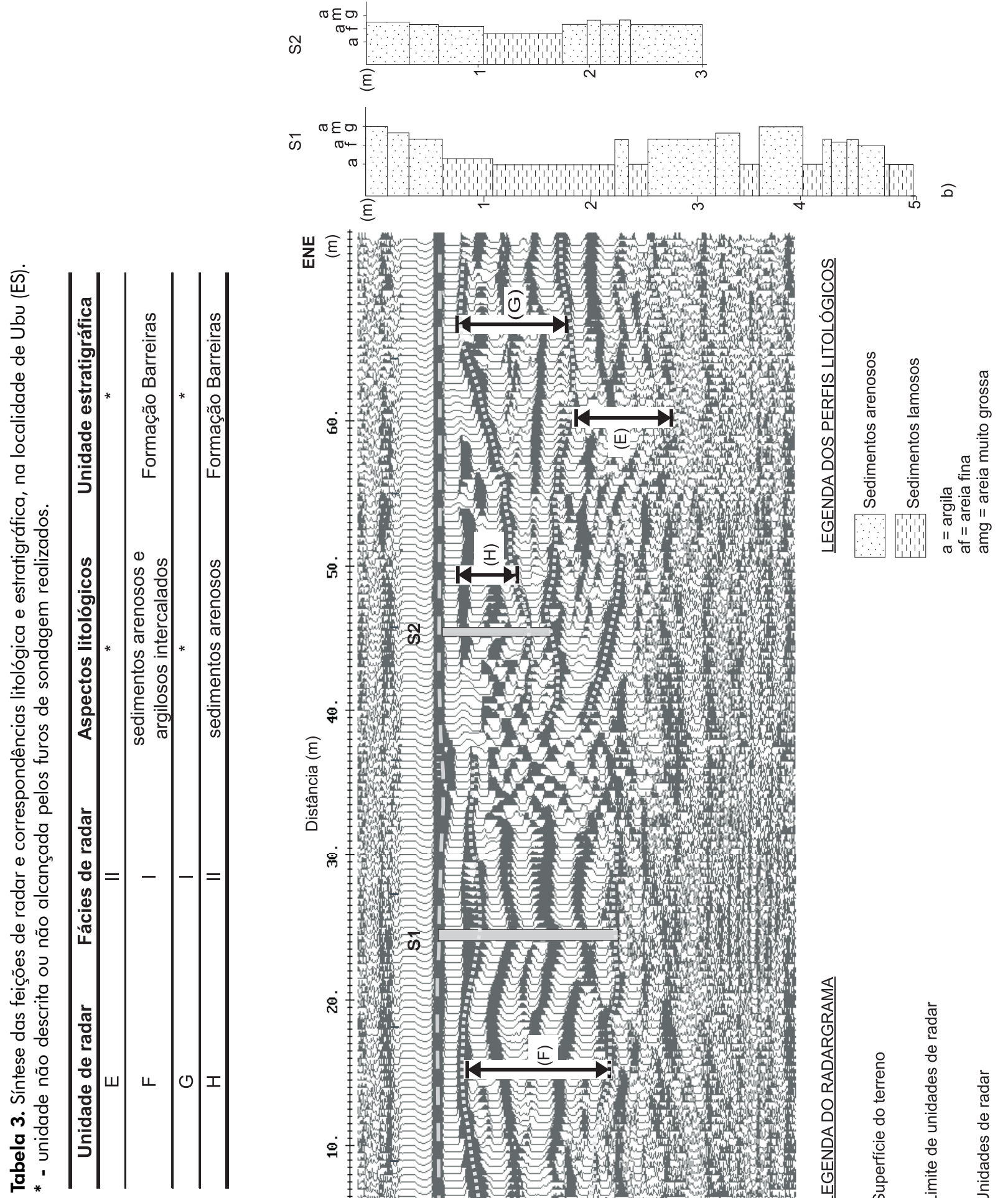

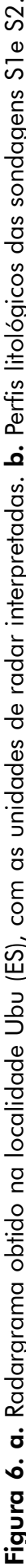




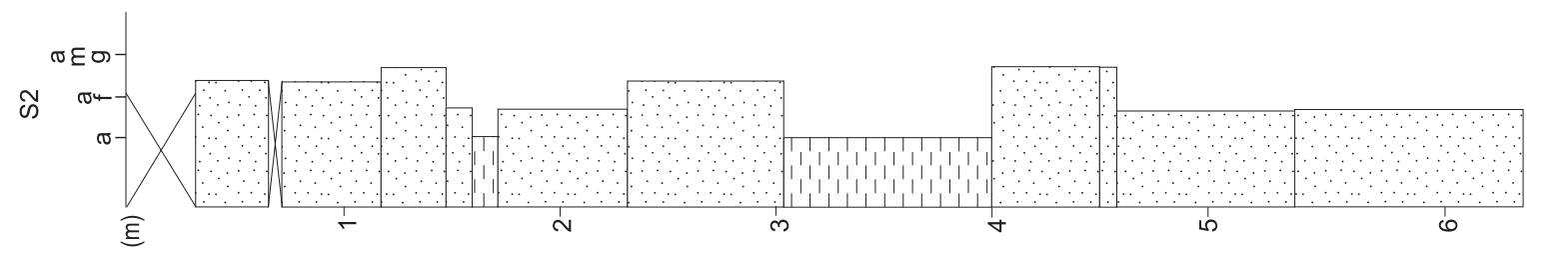

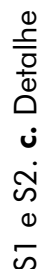
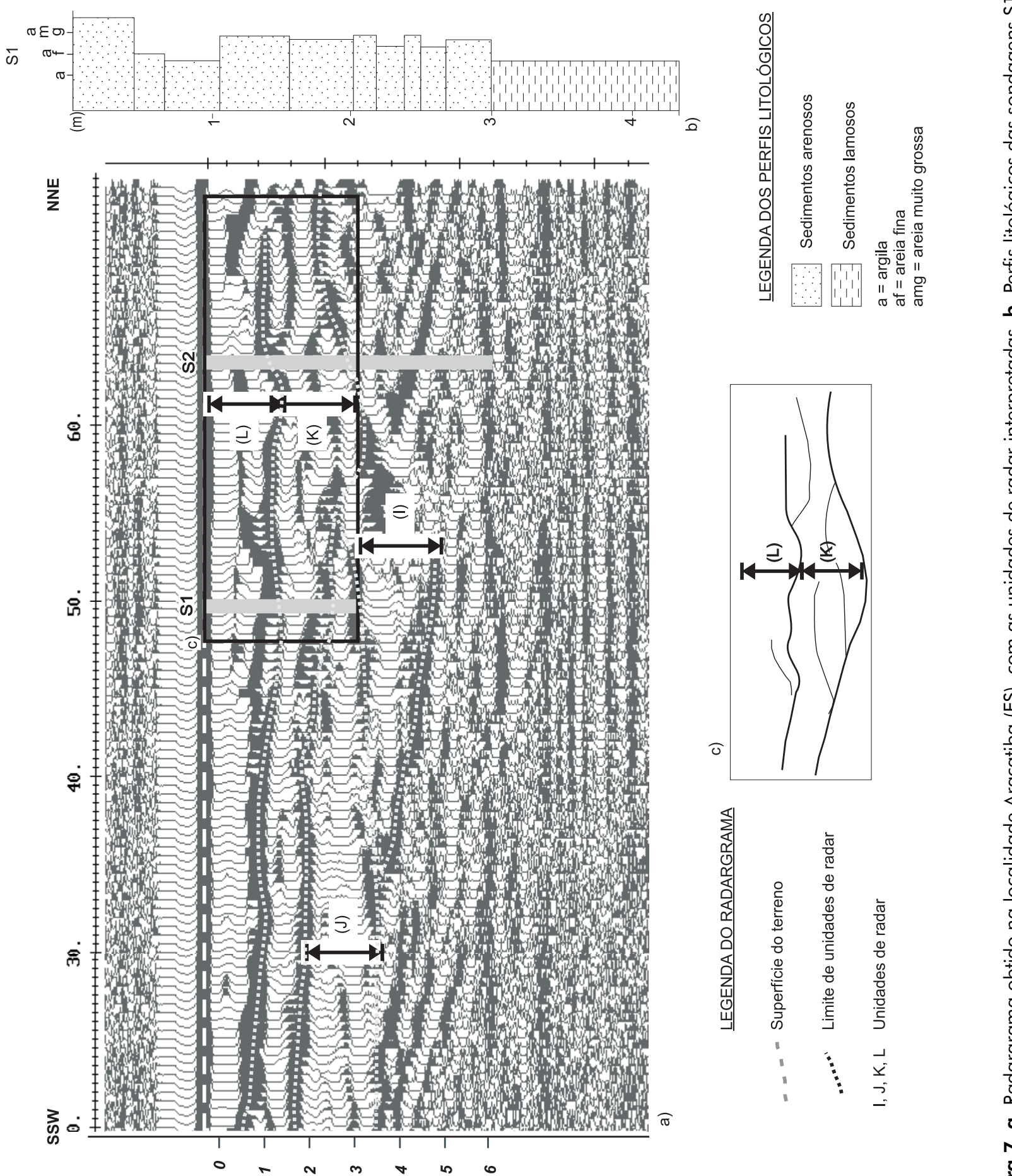

(w ) әpep!̣unjodd

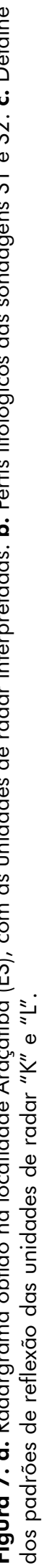


Tabela 4. Síntese das feições de radar e correspondências litológica e estratigráfica, na localidade de Araçatiba (ES).

\begin{tabular}{cccc}
\hline Unidade de radar & Fácies de radar & Aspectos litológicos & Unidade estratigráfica \\
\hline I & $\mathrm{I}$ & sedimentos lamosos & Formação Barreiras \\
$\mathrm{J}$ & $\mathrm{I}$ & sedimentos lamosos & Formação Barreiras \\
$\mathrm{K}$ & $\mathrm{I}$ & sedimentos arenosos & Formação Barreiras \\
$\mathrm{L}$ & $\mathrm{II}$ & sedimentos arenosos & Formação Barreiras \\
\hline
\end{tabular}

\section{CONCLUSÕES}

A técnica de prospecção por reflexão de ondas de radar $(G P R)$ empregada neste estudo, com antenas de freqüência igual a $50 \mathrm{MHz}$, permitiu a obtenção de imagens contínuas e de boa resolução, limitada, no entanto, a profundidades menores do que $10 \mathrm{~m}$.

A assinatura geofísica dos depósitos da Formação Barreiras corresponde a dois padrões de refletores:

1. refletores contínuos, paralelos, às vezes pouco irregulares (fácies de radar I), correspondendo a camadas tabulares de lamitos ou à intercalação de camadas de lamitos e arenosas;

2. refletores ondulados, mais ou menos contínuos, de aspecto entrecruzado, com geometria côncava para cima (fácies de radar II), padrão que corresponde a corpos lenticulares preenchidos por depósitos arenosos com estratificações cruzadas, em sucessões granodecrescentes.

Os trabalhos realizados na região de Quissamã (RJ) apresentaram informações mais completas da relação estratigráfica dos depósitos da Formação Barreiras com o embasamento cristalino e com os depósitos pós-Barreiras. As seções geofísicas investigadas nas localidades Ubu (ES) e Araçatiba (ES) apresentaram padrões de reflexão da fácies de radar II mais bem marcados, o que pode estar relacionado com o menor grau de alteração por pedogênese e ferruginização dos depósitos da Formação Barreiras nestas localidades.

Os depósitos descritos neste trabalho apresentam características litológicas similares aos depósitos desta mesma unidade estratigráfica estudados por outros autores na região Sudeste (Amador, 1982; Tamara, 1995; Morais, 2001). Para os depósitos constituídos pela intercalação de lamitos e areias estratificadas ou maciças, atribui-se uma origem pela alternância dos processos de decantação de finos e fluxos trativos de alta energia pouco canalizados. Para os depósitos em pacotes arenosos granodecrescentes, com ou sem estratificações cruzadas, distribuídos em camadas lenticulares extensas, é atribuída uma origem por fluxos trativos em canais fluviais rasos, com restrita acreção lateral em barras fluviais.

\section{AGRADECIMENTOS}

Agradecemos ao Prof. Dr. Claudio Gerheim Porto (Depto. Geologia/UFRJ), coordenador do projeto "Minerais Pesados em Quissamã (RJ)", desenvolvido em convênio com o Departamento de Recursos Minerais do Estado do Rio de Janeiro (DRM/RJ) e as Indústrias Nucleares do Brasil (INB), no âmbito do qual parte deste estudo foi realizado. Agradecemos ao Instituto de Geociências da UFRJ, ao geólogo Ivar Aptin e aos técnicos Joseilson Rodrigues da Silva e Aldemir França Ferreira (Laboratório de Geografia Física - IGEO/UFRJ), pelo apoio nas atividades de campo. Ao Departamento de Geologia da UFRJ, pelo empréstimo do GPR pulseEkkoIV e ao Núcleo de Estudos do Quaternário e Tecnógeno (NEQUAT) - Departamento de Geografia/UFRJ, pelo empréstimo do trado mecânico. Ao $\mathrm{CNPq}$, pelo apoio financeiro através do projeto de pesquisa (proc. 350565/2003-7) e de bolsas de iniciação científica e de Pós-Graduação. A SAMARCO Mineração S/A, pela liberação de acesso para os estudos na região de Ubu (ES). Agradecemos aos revisores, Dr. Kenitiro Suguio, Dr. Francisco Hilário Rego Bezerra e Dr. David Lopes de Castro, pelas críticas e sugestões a este artigo.

\section{REFERÊNCIAS BIBLIOGRÁFICAS}

AMADOR, E. S. Depósitos relacionados à formação inferior do grupo barreiras no estado do Espírito Santo. In: CONGRESSO BRASILEIRO DE GEOLOGIA, 32., 1982, Salvador. Anais... Salvador: SBG, 1982. v. 4, p. 1451-1460.

AMADOR, E. S.; DIAS, G. T .M. Considerações preliminares sobre depósitos do Terciário Superior do norte do Espírito Santo. Anais da Academia Brasileiras de Ciências, Rio de Janeiro, v. 50, n.1, p. 121, 1978.

HARARI, Z. Ground-penetrating radar (GPR) for imaging stratigraphic features and groundwater in sand dunes. Journal of Applied Geophysics, Amsterdam, v. 36, n. 1, p. 43-52, 1996. 
MADEIRA, C. V.; MELLO, C. L.; PILON, J.; MOURA, J. R. S. O uso do GPR na estratigrafia de depósitos coluviais na região do médio vale do rio Paraíba do Sul. In: CONGRESSO DA ASSOCIAÇÃO BRASILEIRA DE ESTUDOS DO QUATERNÁRIO, 6., 1997, Curitiba. Resumos Expandidos... Curitiba: ABEQUA, 1997a. p. 194-198.

MADEIRA, C. V.; MELLO, C. L.; PILON, J.; MOURA, J. R. S. Applications of GPR to Quaternary sediments of Southeastern Brazil. In: INTERNATIONAL CONGRESS OF THE BRAZILIAN GEOPHYSICAL SOCIETY, 5., 1997, São Paulo. Expanded Abstracts ... São Paulo: SBGf, 1997b, v. 1, p. 544-546.

MADEIRA, C. V. Estratigrafia e arquitetura de depósitos sedimentares quaternários no SE do Brasil, com base em reflexão de Ondas de Radar. 2001. 269 f. Tese (Doutorado) - Depto. de Geologia, IGEO, Universidade Federal do Rio de Janeiro, Rio de Janeiro, 2001.

MORAIS, R. M. O. Estudo faciológico da Formação Barreiras na região entre Maricá e Barra de Itabapoana, estado do Rio de Janeiro. 2001. 113 f. Dissertação (Mestrado) - Depto. Geologia, IGEO, Universidade Federal do Rio de Janeiro, Rio de Janeiro, 2001.

SUGUIO, K.; NOGUEIRA, A. C. R. Revisão crítica dos conhecimentos geológicos sobre a Formação (ou Grupo?) Barreiras do Neógeno e o seu possível significado como testemunho de alguns eventos geológicos mundiais. Geociências, São Paulo, v. 18, n. 2, p. 461-479, 1999.

TAMARA, G. Contribuição ao estudo do Grupo Barreiras na Região Metropolitana de Vitória (ES). 1995. 73 f. Dissertação (Mestrado) - Depto. Geologia, IGEO, Universidade Federal do Rio de Janeiro, Rio de Janeiro, 1995.

SCHOBBENHAUS, C.; CAMPOS, D. A.; DERZE, G. R.; ASMUS, H. E. Geologia do Brasil: texto explicativo do mapa geológico do Brasil e da área oceânica adjacente incluindo depósitos minerais, escala 1:2.500.000. Brasília: DNPM, 1984. 